\title{
Reseña de: Ana M. González Ramos (Dir.). Mujeres en la ciencia contemporánea. La aguja y el camello. Barcelona: Icaria, 2018.
}

\author{
Inés LOZANO CABEZAS \\ Facultad de Educación \\ Universidad de Alicante
}

En la Educación Superior, espacio en el que se desarrolla el conocimiento científico, todavía se identifican obstáculos y dificultades que impiden progresar a las académicas y las científicas en igualdad de condiciones al resto de sus compañeros. La cultura androcéntrica se mantiene presente y ello hace que la producción científica quede en manos de algunos y continúe con la invisibilidad de las científicas y de las profesoras universitarias. La obra que voy a reseñar presenta las evidencias científicas analizadas del Proyecto GENERA: Generación de una economía del conocimiento más inclusiva y competitiva, en la que se da voz a los relatos de vida del personal científico, con el propósito de conocer y valorar las trayectorias personales y profesionales de las mujeres y de los hombres durante su carrera profesional en el contexto universitario. Se trata de un proyecto que aborda diversas metodologías de investigación (asume, por tanto, «un análisis plurimetodológico») y contrasta sus evidencias a través de una revisión bibliográfica exhaustiva basada principalmente en estudios de género y universidad. La precisión de su lenguaje y la redacción clara que se desarrolla a lo largo del texto coindice con la afirmación de la profesora M. Antonia García de León (firmante del capítulo quinto) al considerar este libro como una excelente obra didáctica que ayuda a comprender y a reflexionar sobre la situación de las académicas y las investigadoras en la sociedad actual. Además de las autoras que participan

Los contenidos de la revista se publican bajo una licencia de Creative Commons Reconocimiento 4.0 Internacional (CC BY 4.0)

Feminismo/s 32, diciembre 2018, pp. 373-377 
en esta edición, la relevancia de esta obra viene avalada por los prólogos del antiguo Secretario General de Universidades y, principalmente, por la actual presidenta de la Asociación de Mujeres Investigadoras y Tecnólogas (AMIT), Joaquina Álvarez-Marrón, que destaca el carácter innovador de este texto que analiza y cuestiona de manera sistemática las discriminaciones aún vigentes en el ámbito científico.

Mujeres en la ciencia contemporánea. La aguja y el camello se desarrolla en un total de seis capítulos. La introducción la inicia la directora del libro, Ana M. González Ramos, la cual cierra el mismo exponiendo las posibles propuestas para la igualdad efectiva de mujeres y hombres en el ámbito científico. El propósito de este texto intenta visibilizar las problemáticas y dificultades de las mujeres en el Espacio Europeo de Investigación que aún sigue bajo los fundamentos de la cultura patriarcal, a saber: en los sesgos de género y la promoción de meritocracia. En este sentido, Ana M. González manifiesta que este libro quiere resaltar la importancia de mejorar las estructuras o modelos científicos para crear espacios en un lugar «más justo y útil socialmente» para todas las personas que dedican su trabajo a la contribución del conocimiento científico.

En el primer capítulo, Ana M. González Ramos nos explica las causas o razones de la deserción de las mujeres investigadoras. El mayor número de abandonos se produce por causas externas que suelen estar referidas al finalizar el periodo de doctorado, en sus primeros años de contratación laboral o en la edad madura para decidir ser madres. En estos momentos la mayoría de las mujeres debe abandonar o rechazar otros proyectos a nivel profesional, aspecto que manifiestan los participantes en este estudio cualitativo. Se pone en relieve que aún sigue vigente el modelo androcéntrico en la ciencia y cabe, por tanto, repensar el mismo para lograr la igualdad efectiva en la formación inicial académica e investigadora de las mujeres.

En la última década se ha detectado una alta intensificación de la movilidad de los profesionales de la Universidad a centros de investigación de excelencia. El desplazamiento a estos centros supone un enriquecimiento para su formación en su ámbito de conocimiento y un sello de calidad en su trayectoria científica. En este sentido Beatriz Revelles-Benavente describe los ambientes de trabajo en estos centros, caracterizados por su nivel de productividad científica y la excelencia de los grupos de investigación que los

Feminismo/s 32, diciembre 2018, pp. 373-377 
constituyen como referencia a nivel internacional. A pesar de ello, el modelo de gestión científica de los mismos aún está amparado por el sistema patriarcal, provocando «situaciones de desventaja para aquellas personas que, por razones de edad y género, se entran en una posición más vulnerable» (73). La autora afirma que esta vulnerabilidad depende de la marketización de sus currículos profesionales y perjudica directamente a las mujeres que siguen desempeñando su doble tarea: familia y trabajo. A lo largo de este capítulo la autora analiza los relatos de las mujeres que han desarrollado tareas en los citados centros, y por lo cual se demanda una solución de igualdad efectiva para el desarrollo profesional de las investigadoras y los investigadores que acuden a estos centros.

Las motivaciones extrínsecas e intrínsecas suponen también un factor influyente con respecto a la carrera académica e investigadora. Nora Räthzel, autora del capítulo tres, analiza los discursos de las mujeres y los hombres sobre su trayectoria vital (y profesional) diferenciando entre las citadas motivaciones. Tanto las influencias personales individuales (nos dice la autora) como las colectivas suponen elementos decisivos para iniciarse en esta profesión y continuar en ella. Se describen situaciones de incertidumbre, apoyos recibidos por los mentores y por sus colegas o los efectos de la «doble microdiscriminación» que les ha hecho quebrar el «techo de cristal»o continuar adheridas al «suelo pegajoso». A pesar de que los hombres también describen algunas de estas motivaciones, la autora pone de manifiesto que «las mujeres, que se debaten en un contexto complejo, y que tienen expectativas construidas a partir de roles de género difuso» (121).

Las redes colaborativas son una herramienta que promueve la igualdad de oportunidades de las mujeres en la Academia y en la ciencia, a través de la cooperación entre todos sus miembros, pero se destaca muy especialmente las actitudes de solidad, empatía e inclusión. En el capítulo cuarto, Esther Torrado Martín-Palomino analiza el impacto de estas redes de cooperación de las mujeres que ha permitido la consecución de logros significativos en el desarrollo profesional y científico de aquéllas. La investigación que se expone en este capítulo evidencia que este tipo de redes supone un modelo que facilita la continuidad y promoción de las mujeres, da más visibilidad a logros y triunfos de las académicas y contribuye, en cierta manera, a la ruptura de los liderazgos de las redes de poder masculino.

Feminismo/s 32, diciembre 2018, pp. 373-377 
M. Antonia García de León nos describe en el capítulo quinto la presencia aún hegemónica de lo masculino en la Academia. Para ello parte de su investigación realizada en el año 1982 que tituló como «élites discriminadas». A través de un estudio cartográfico en relación al poder y al género, la autora realiza una revisión teórica haciendo referencia a diversas autoras y diversos autores (Amorós, Castells, Subirats, Bourdieu, entre otros) y ejecuta con maestría las distintas fronteras del género para situar el binomio entre género y poder como un ejemplo de los «claroscuros del género». Este capítulo invita a reflexionar acerca de las conquistas del feminismo y manifiesta que aún quedan logros por conseguir. La única manera de continuar con la conquista de la igualdad solo es posible gracias a la acción común, pues con ello se producirá «la descolonización del imaginario de género» (172).

En esta vertiginosa sociedad de producción acelerada no se queda excluida la producción «exagerada» que se nos exige al personal docente e investigador en el contexto universitario para poder promocionar. La Academia aún continua rigiéndose por el lema «produce o perece» muy vinculado al término «neogerencialismo». Desde una perspectiva de género sobre el tiempo y el esfuerzo de trabajo en la Academia, Ester Conesa Carpintero presenta el último capítulo de esta obra haciendo referencia a los efectos colaterales de este término y la emergencia del modelo slow science que permiten reflexionar sobre el modelo actual de ciencia basado en la evaluación y medición de las producción científica. Este capítulo concluye con la presentación del modelo basado en una ética feminista del cuidado para mejorar la calidad de vida de las personas que trabajan en la Academia y que suponga un reconocimiento de la igualdad y la diversidad de las mismas.

El libro finaliza con treinta y dos propuestas que ayudarán en la mayor medida a reestructurar el modelo científico, en el que la colaboración mutua permitirá la integración auténtica de cada uno de todos los miembros que trabajan en la contribución del conocimiento científico. Ello supone, por tanto, repensar las estrategias políticas situando al androcentrismo en un segundo lugar para conseguir espacios y zonas de igualdad. Como se muestra en esta obra, existe abundante literatura científica a nivel nacional e internacional que evidencia que la gestión y la generación del conocimiento aún siguen controladas por el poder masculino, especialmente en las instituciones

Feminismo/s 32, diciembre 2018, pp. 373-377 
Reseña de: Ana M. González Ramos (Dir.). Mujeres en la ciencia contemporánea.

La aguja y el camello. Barcelona: Icaria, 2018.

universitarias. Considero, por tanto, que es hora de actuar por parte del poder político (aún masculino), para que la igualdad en la Academia sea un hecho del pasado y no un elemento de discusión del presente.

Feminismo/s 32, diciembre 2018, pp. 373-377 